Stella, F. (2014) Engaging with 'impact' agendas? Reflections on storytelling as knowledge exchange. In: Taylor, Y. (ed.) The Entrepreneurial University: Engaging Publics, Intersecting Impacts.

Palgrave Macmillan, Basingstoke, pp. 105-124. ISBN 9781137275868

Copyright (C) 2014 The Author

A copy can be downloaded for personal non-commercial research or study, without prior permission or charge

Content must not be changed in any way or reproduced in any format or medium without the formal permission of the copyright holder(s)

When referring to this work, full bibliographic details must be given

http://eprints.gla.ac.uk/96421/

Deposited on: 29 August 2014

Enlighten - Research publications by members of the University of Glasgow http://eprints.gla.ac.uk 
Stella, F. "Engaging with 'impact' agendas? Storytelling as knowledge exchange", in Taylor, Y. (ed.) The Entrepreneurial University. Public Engagements, Intersecting Impacts. Palgrave, 2014. ISSN 9781137275868.

\section{Engaging with 'impact' agendas? Reflections on storytelling as knowledge exchange}

Francesca Stella ${ }^{1}$

The 'impact agenda', that is the whole gamut of initiatives related to knowledge exchange and public engagement that have been articulated in recent years, has had and continues to have a significant shaping influence on the way in which academics carry out their research. Within a UK context, the Research Excellence Framework (2008-2013) has made an explicit engagement with this agenda virtually compulsory for research-active academics by introducing 'impact' as a new criteria on which the research performance of universities, departments and individual researchers is assessed. The new emphasis on impact, defined as the 'demonstrable contribution' that research makes 'to society and the economy ${ }^{\prime 2}$ beyond specialist academic audiences, has generated much discussion and controversy among academics.

The 'impact agenda' has been critiqued on a number of grounds, ranging from diluting standards of academic excellence (Jump 2012), to limiting academic freedom by tying fundable academic enquiry to policy objectives, to concerns about the difficulties and costs involved in assessing 'impact' (Martin 2011). The widespread perception that academic autonomy is increasingly threatened by the twin forces of 'audit culture' and the commodification of higher education has been exacerbated by the broader climate of economic austerity and related cuts in university funding. Meanwhile, 'impact' itself remains a poorly understood and nebulous concept even as 'impact case studies' are embedded within REF criteria and scores. The difficulty in clearly defining the rules of the game stems from the fact that each discipline, research community and individual researcher has their

\footnotetext{
${ }^{1}$ This paper originates in the project 'Translating Russian and East European cultures: Exchange and communication within a multidisciplinary and multicultural Area Studies context'. (AHRC grant number AH/I001557/1, funded under the AHRC Research Networking Scheme; PI: Dr Jon Oldfield; co-I: Dr Katarzyna Kosmala ). It would not have been possible to write this chapter without the input, insight and support of all the people who contributed their ideas and skills to the project. The immediate stimulation to write this paper came from discussions with Jon Oldfield, and I would like to thank him especially for his constant input as well as his very thoughtful and thorough feedback on different drafts of the chapter. Whilst other colleagues were involved at various points in the storytelling events, special thanks go to Elwira Grossman, whose leadership, energy and enthusiasm as co-organiser of the storytelling events made them so enjoyable for everyone involved.
}

${ }^{2}$ http://www.rcuk.ac.uk/kei/impacts/Pages/meanbyimpact.aspx. 
own notion of 'impact' as it pertains to their work. Nonetheless, there is a real danger that lack of clarity, compounded with the obligatory compliance to impact assessment, may encourage a strategic 'game-playing' and a random incentivisation of short-term 'impact' activities by university management, rather than a vision of what meaningful engagement with non-academic publics may look like.

In the light of this, the basic aim of this chapter is to reflect critically on the difficulties of implementing impact agendas with recourse to a Research Networking initiative (Translating Russian and East European Cultures), funded by the Arts and Humanities Research Council (AHRC). The chapter focuses on knowledge exchange, since a key and recurring point of reflection throughout the initiative concerned the nature and practice of knowledge exchange (cf. Mitton et al. 2007) across academic and non-academic 'communities of practice' (Wenger 1998). This topic is explored here though a case study of one particular strand of the TREEC Network Initiative dedicated to storytelling. The heart of the chapter reflects on storytelling as a way to facilitate "knowledge exchange', as well as on the ability of the storytelling events organised to bring together different publics. Whilst critical of 'impact agendas', I proceed from the position that, as publicly funded researchers, academics have a responsibility to contribute to the wider society through their knowledge, skills and resources, and that beyond strategic compliance to impact assessment 'knowledge exchange', broadly defined, has always been and should remain an integral part of university activities.

\section{Critical engagements with 'impact' agendas}

Public engagement and knowledge exchange agendas have emerged as key forces shaping the Higher Education sector underpinned by long-standing debates over the role and purpose of universities as well as discussions over the future sustainability and success of the higher education sector within a global context. At the same time, the precise linkages between these various elements are often hard to determine and much confusion remains with respect to issues of definition and measurement. The emergence of such agendas has been further entrenched in recent years by the global economic crisis and associated austerity cuts, whereby the value of knowledge exchange and its associated 'impact' is often framed in utilitarian or else market-driven terms.

The vast sweep of university life ensures that while many academic disciplines are able to work to such an agenda with limited additional effort, there remains a substantial chunk of academic activity which occupies a more uncertain middle-ground whereby knowledge exchange beyond the academy is more difficult to determine or capture and the utility of any output difficult to quantify. While 
wary of over- generalising, it is probably fair to say that the arts and humanities and to a lesser extent the social sciences have found the emerging agendas particularly problematic in contrast to the so-called STEM disciplines (Science, Technology, Engineering and Mathematics). This has little to do with the relative worth of the different areas of scientific endeavour but instead reflects the framing of the knowledge exchange agendas and the emphasis placed on concrete and tangible evidence of associated impacts. In recognition of this, Research Councils as well as evaluative exercises such as the Research Excellence Framework (REF2014, 2012) have flagged a whole range of worthy impacts in an effort to acknowledge the complexity of this issue. The extent to which the utilitarian emphasis dominates is difficult to say; nevertheless, there is a perception, rightly or wrongly, that applied research with a demonstrable 'impact' for private users and non-academic beneficiaries, and with the potential to bring financial returns to higher education institutions (HEIs) remains at the heart of the process. Such perceptions are reinforced by the emphasis placed on the natural sciences and technology subjects in recent years, which is impacting on arts and humanities and social sciences subjects, more or less implicitly designated as non-priority areas in policy documents such as the Brown Report (Department for Business, Innovation and Skills, 2010).

To a large extent, the uncertainties over the impact and knowledge exchange agendas are linked to the broader uncertainties over the purpose and role of universities in contemporary society (see Collini, 2010). The resulting conceptual vacuum provides a clear opportunity for marketising and related agendas to play a shaping role and such developments are viewed warily by many academics not simply because of the threat they pose to existing 'ways of doing things', but for more nuanced and meaningful reasons linked to the perceived role that universities should play in society. For example, Holmwood (2011b) and Burawoy (2011) contend that current agendas, driven by the marketisation of the Higher Education system and by an increasingly pervasive audit culture (see Shore and Wright 1999), undermine the notion of higher education as a public good and as a social right, which takes us back to the issue concerning the purpose and role of the university in the early $21^{\text {st }}$ Century.

Amongst the many possible faces of the contemporary university I favour one that places an emphasis on its public mission in its broadest sense, which lies in supporting not only research and teaching activities (knowledge creation and transmission), but also a variety of outside activities through an active engagement with non-academic publics. Debates about social justice, access to higher and further education and the public role of universities go back a long way (Skeggs 1997; Reay 2004; Reay, Miriam and Ball 2005). As Calhoun (2006: 8) notes, much thinking about the role of research, scholarship and teaching in higher education is implicitly based on two Enlightenment 
ideals: 'that knowledge can be at once authoritative and democratic and that [it] can simultaneously inform expert instrumental use and public debate'. Although there seems to be a broad consensus among UK-based academics about the public role of universities, not least because British Higher Education Institutions are predominantly state-funded, a fundamental tension exists between the two dimensions highlighted by Calhoun (an emphasis on academic excellence as a value in itself visa-vis a concern for widening access to higher education and to the knowledge produced by universities; an emphasis on policy-relevant expertise vis-a-vis an interest in how wider publics may benefit from it ). This tension is reflected in disagreements about what the key public functions of universities should be. I proceed from the position that the public role of universities should go beyond the government-defined objectives of contributing to the 'knowledge economy' and producing an educated workforce, and strive to fulfil a broader social role in public life by contributing to what Holmwood (2011a) calls 'collective intelligence'. Holmwood argues that a fundamental function of universities is their role in facilitating public debate and widening access to knowledge, thus enabling different publics to represent themselves, rather than in inputting 'government and corporate decision-making independently of the participation of the wider public' (Holmwood 2011:25). The approach to 'impact' presented in this chapter approach encompasses many of the current trends extant within universities, but arguably provides a clearer sense of emphasis on the democratising role of universities in broadening access to knowledge and skills and in facilitating the participation of diverse publics in social and cultural life.

The relationship between 'expert' publics and broader publics lies at the heart of Holmwood's 'Manifesto for a Public University', whose sentiments I broadly share. The nature of this relationship is also central to debates about 'knowledge exchange', understood as the two-way flow of knowledge, expertise and skills between academic and non-academic publics, and 'public engagement', defined as 'the myriad of ways in which the activity and benefits of higher education and research can be shared with the public' ${ }^{3}$. I maintain that a critical engagement with 'knowledge exchange' and 'public engagement' can provide a fruitful means for shaping future research agendas, as part of a broader effort to understand how universities can function for the benefit of wider publics. As part of this, I note the efforts of academics to subvert the market-logic of state policy-driven impact agendas through methodological innovation such as the recent surge in interest surrounding Participatory and Action Research (PAR), where engagement with knowledge exchange is driven by a commitment to foster social justice and change. This approach has produced interesting work exploring novel ways to work collaboratively with research participants, end users and stakeholders, and promoted the notion of knowledge as co-produced: 'research may inform

\footnotetext{
${ }^{3}$ https://www.publicengagement.ac.uk/what
} 
society, but its own agendas, design, conduct and outcomes are also profoundly informed and shaped by various users, publics and participants' (Pain et al. 2011: 185-86; Kindon et al. 2010). An interesting development within collaborative and action research has been the deployment of artsbased methods as a way of accessing research participants' experiential knowing, and to represent it in a variety of narrative and visual forms (Liamputtong and Rumbold 2008; Pratt and Johnson 2007). At the same time, I also feel that existing initiatives in this area require more critical assessment. There are two general issues here; first, the noted 'audit culture', now entrenched in university life, arguably promotes instrumental, un-reflexive and acquiescent approaches to knowledge exchange as simply another box that needs to be ticked in order to fulfil REF requirements, assist promotion applications and so on. Second, and linked to this, there is a sense that while significant amounts of RCUK as well as institutional funding are being directed towards the implementation and evaluation of 'impact' agendas, the evaluation of the effectiveness of such activities is perhaps less robust than in other areas of scholarly endeavour. With so much continued uncertainty over what is 'impact' and how might it be 'measured', it seems unlikely that evaluation will be effective across the board. Paradoxically, an enhanced evaluation system may make the impact assessment more burdensome and costly, potentially contributing to the spiralling costs (economic and otherwise) of the audit infrastructure itself, which are ultimately born by already overstretched academic staff (Martin 2011). Critical, empirically based reflections on the benefits, discomforts and limitations of academic engagement with 'knowledge exchange' are timely and can hopefully feed into a much needed reassessment of the REF exercise and related audit culture, while also informing broader debates about how universities can function for the benefit of wider publics.

\section{Impact agendas and Area Studies}

The process of engaging with the wider public, and of sharing knowledge to non-academic practitioners and end users has long been part of academic practice, not least for area studies scholars (Flynn, Kay and Oldfield 2008). Indeed, academic knowledge and insights derived from a deep study of former socialist countries have formed the basis of numerous forays beyond the confines of the university during the course of the last century. In the case of the former Soviet Union, the UK government placed great emphasis on the strategic value of such knowledge and enrolled scholars in the production of technical overviews and evaluations epitomised by initiatives such as the Admiralty Handbooks ${ }^{4}$ (Matless, Oldfield and Swain 2007). The potential strategic role of

\footnotetext{
${ }^{4}$ The Admiralty Handbooks (Naval Intelligence Handbooks) were produced by academics based in Oxford and Cambridge during the Second World War for many parts of central and eastern Europe (and beyond), and
} 
academics was most obvious during the Cold War period and links between academia and the state were not uncommon, albeit this engagement was shaped by the geohistorical context of the Cold War and thus was far from unproblematic (Szanton, 2004). Scholars of what might be broadly termed Slavonic and East European studies have also been adept at producing publications with a relatively wide appeal, moving well beyond the narrow confines of the disciplinary journals (Nove, 1992; Wedel, 2001; Figes, 2002). Similarly, media output together with active participation in the political and social issues of former socialist countries have also been a feature of this community of scholars over the years (Pilkington and Omel'chenko 1997; Flynn, Kay and Oldfield 2008; Stella 2008a). This is not to say that the activities of academics beyond the 'ivory towers' do not require additional thought and critical reflection; however, it does imply that the 'impact' and knowledge exchange agendas that have enveloped the UK Higher Education sector in recent years are rather more politically and institutionally strategic than novel in nature. It should also be noted that Slavonic and East European Studies has responded to contemporary impact agendas, helped considerably by strategic investment in the Language Based Area Studies (LBAS) more broadly by the Research Councils, HEFCE and the SFC, which has enabled funding to be channelled into a range of 'outreach' activities (Dunn, 2013). At the same time, the considerable reach of Language-Based Area Studies, encompassing both arts and humanities as well as social science disciplines, means that it has been peculiarly vulnerable to the noted emphasis placed on STEM-related activities in recent years. This illustrates the paradoxes of audit culture: while foreign languages, like other arts subjects, are seemingly dismissed as superfluous, elitist and dispensable subjects, 'internationalisation' is increasingly portrayed as crucial to the development and sustainability of UK HEls. The dispensable status attributed to the teaching of foreign languages, however, betrays internationalisation as a process driven by the neoliberal logic of finding new global markets, rather than motivated by the desire to sustain meaningful exchanges of knowledge, expertise and experiences across geographical and linguistic boundaries.

\section{Translating Russian and East European Cultures: a case study}

From the above, it is hopefully clear that while I share widespread concerns over the nature and character of the current impact and knowledge exchange agenda I also feel that such work, broadly defined, is an important and integral as well as historically-relevant element of university activity. As 
such, I are less concerned here with undermining the existing agendas and more interested in determining how such activity might actually be effective moving beyond the perceived instrumentalisation and box-ticking noted above. To this end, the chapter reflects on my involvement in an AHRC-funded Research Networking initiative (Translating Russian and East European Cultures) which took place over an 18-month period during 2011-12.

The Network grew out of the long-term interests of its constituent members who had collectively spent many years trying to extol the virtues and relevance of scholarly work related to Slavonic and East European Studies as well as initiate conduits for their work with other sections of society both within and beyond the UK. The Network was shaped by the multi-disciplinary Area Studies context as well as the cross-institutional characteristics of the Centre for Russian, Central and East European Studies (CRCEES), an intra-universities Centre for Excellence. In total, ten people from CRCEES partner institutions from across Scotland and the North of England were involved in the activities of the network; the partner institutions were the University of Glasgow, the University of Edinburgh," the University of the West of Scotland and the University of Nottingham ${ }^{5}$.

The initiative aimed to build capacity and good practice in knowledge exchange within Area Studies around the central theme of 'translating culture' broadly interpreted. It further aimed to establish collaborations with a range of non-academic user groups and partner organisations. Official partners of the TREEC Network Initiative included the Scotland-Russia Forum, the Scottish Storytelling Centre and a number of Glasgow-based secondary schools; in addition, at different points during the course of the initiative other collaborators and audiences were involved, including a range of arts practitioners, voluntary sector organisations, language practitioners and postgraduates. A key element of the initiative also revolved around the exploration of Area Studies' potential to facilitate innovative means of knowledge exchange given its multidisciplinary basis and associated scope for drawing innovatively from across the arts and humanities and social sciences.

It was intended that the TREEC initiative would provide a space to deconstruct the nebulous 'knowledge exchange' agenda and discuss and reflect on key issues involved in implementing it. In keeping with the general confusion surrounding the 'impact' and knowledge exchange agendas noted above, Harry and McKenzie (2012) argue that the diverse and confusing terms used in the context of 'impact' agendas (e.g. knowledge transfer, knowledge exchange, knowledge translation, knowledge utilisation etc) imply different relationships between academics, practitioners and publics. The notion of 'knowledge exchange' which both implicitly underpinned and gradually

\footnotetext{
${ }^{5}$ For more details about the TREEC initiative see http://www.gla.ac.uk/schools/socialpolitical/research/centraleasteuropeanstudies/projects/treec/newsandev ents/.
} 
crystallised over the duration of the TREEC project was that of a multifocal process involving the interfacing of different publics; a key recurring theme of discussion and reflection centred around the nature of knowledge exchange, the successes and limitations of the exchanges facilitated through the TREEC Network Initiative, and the barriers to knowledge exchange practice.

Setting up and running the TREEC initiative raised questions about the very nature and meaning of knowledge exchange, for example, whose knowledge was being exchanged, and for what purposes? It is often assumed that knowledge exchange is about communicating academic knowledge to nonacademic audiences; yet communicating with wider publics can be made more effective and engaging by drawing on skills that as academics we did not necessarily master, and by collaborating and learning from non-academic practitioners. Thus, the activities of the TREEC Network started from the premise that meaningful knowledge exchange is a multifocal, multidirectional process. Furthermore, knowledge transfer and knowledge exchange are typically defined in policy documents as area of activities related to academic research; yet this implies a specific vision of universities which privileges their role as producers of 'expert knowledge' over their educational vocation of providing learning and stimulating critical thinking within and beyond their core student population. Indeed, one of the reasons why many academic staff involved in the TREEC Network were wary of the 'impact agenda' is that it was perceived as fundamentally disconnected from the traditional teaching and research core remit of Higher Education Institutions, while placing additional demands on their time and workloads. A holistic vision of universities as institutions, where research and learning are seen as equally important and interdependent spheres of activities, was favoured as opposed to the notion of research as a more worthwhile endeavour, in keeping with a shared understanding of the public role of universities in democratising access to learning and critical thinking. Thus the TREEC Network did not narrowly focus on the dissemination of specific 'research findings', or even on the co-production of knowledge with non-academics, although some areas of activity involved elements of participatory action research, particularly work in schools. Most strands of the Network's activities, and the storytelling events in particular, aimed to explore the potential of 'knowledge exchange' initiatives to bring together diverse publics, to create opportunities for dialogue, and to make space for learning and debate outside of the 'Ivory Tower'.

One of the key strands of the TREEC project focussed on storytelling, and aimed to explore its potential as a means to facilitate engagement with diverse publics and to navigate cultural, linguistic and disciplinary boundaries ${ }^{6}$. The remainder of the chapter reflects on how different publics were

\footnotetext{
${ }^{6}$ Other strands of the initiative included: engagements with policymakers on the place of language teaching in the Scottish education system; joint projects with arts practitioners on the theme of translating cultures; and collaborations with schools and voluntary sector organisations aimed at facilitating cross-cultural exchanges.
} 
brought together through the storytelling events, and how knowledge was 'exchanged' (i.e. shared and circulated) across them. Through my involvement in the storytelling events I came to understand the interfacing of different publics as exchanges across different 'communities of practice', defined by Wenger (1998) as relatively loose social networks whose activities revolve around 'the sustained pursuit of a shared enterprise'. These communities function on the basis of shared practices, but also operate as learning communities, since membership in these communities (work-based, school-based, or revolving around artistic, leisure or political activities) also involves learning ways of getting things done and developing shared 'routines, rituals, artefacts, symbols, conventions, stories and histories' (Wenger 1998:6). Membership in a community of practice in turn feed into shared (professional, social, political) identities. Thus, academic networks (be they discipline-specific or multidisciplinary, such as the TREEC initiative), arts-based practitioners groups (in this specific case, storytellers) and specific initiatives or places which facilitate the (serendipitous) gathering of wider publics (the Glasgow Women's Library, LGBT History Month, the Scottish Storytelling Centre) can all be loosely defined as communities of practice.

Amongst the academic staff involved in the storytelling events, our shared multidisciplinary area studies background and context (CRCEES) facilitated collaboration and the crossing of disciplinary boundaries. Nonetheless, certain hesitancies and discomforts remained, particularly around whether the project could overcome institutional barriers and perceived hierarchies of value between arts and social sciences disciplines, different comfort levels in experimenting with storytelling and diverse understandings of how fiction and storytelling performances could be reconciled with the aims of disseminating social sciences research findings. Negotiating collaborative links with non-academic community of practices, and particularly with arts practitioners and storytellers, proved to be more complicated, as it involved bridging distances and negotiating relations across two very different communities of practice, with different working cultures, priorities and understandings of storytelling.Securing the initial collaboration with the Scottish Storytelling Centre (SSC) was relatively unproblematic, as the relationship was considered beneficial by both academic staff and representatives of the SSC.: it would allow the TREEC project to draw on the skills and expertise of professional storytellers and use the Centre facilities, whilst the SSC was keen to develop networks with storytellers from Russia, Central and Eastern Europe, as part of a traditional international engagement but also in view of the organisation of a festival with a specific geographic focus on the region in October 2012. Building rapport and working relationships, , however, took time, effort and careful negotiation. Personal relations and ideas developed over the duration of the TREEC project through the participation of a representative of the SSC in the TREEC project's steering group 
meetings and in other TREEC events, and through academic staff's visits to the SSC and to regular gatherings of the Better Crack Club, a Glasgow-based group of storytellers. Additional informal meetings and email exchanges took place to discuss the concept, format and key themes of the events, as well as the venues and people to involve. For the academic staff involved, organising the storytelling events also involved learning about storytelling practices and communities, and developing an awareness of the broader context in which storytellers worked. Indeed, working together and finding common ground involved unpacking and coming to terms with different understandings of storytelling in the first place. On the one hand, the professional and amateur storytellers we worked with were chiefly interested in storytelling as a craft which involved improvising on a repertoire of traditional folk stories, fairly tales and ballads; performances were mainly about trading stories in a friendly space, delivering a story effectively and entertaining an audience. On the other hand, the academic staff involved were keen to explore the use of storytelling performances for a variety of purposes, including teaching and learning, therapy and memory, and to draw on the tradition of radical storytelling, where stories are explicitly used to give a voice to marginalised social groups, to challenge dominant discourses and to subvert commonsense perspectives (Cameron 2011; Mündel 2003; Pratt 2009). In the end, it was decided to organise two separate but related sets of storytelling events to make the most of the collaboration with the SSC and of the expertise of professional storytellers, while also pursuing academic staff interest in the political possibilities of storytelling, and in experimenting with storytelling as part of our academic practice. Thus, one of the lessons learned about barriers to knowledge exchange practice is that working across different communities of practice requires coming to a mutual understanding of different professional identities, areas of expertise, motivations and interests, pressures and priorities, and that this understanding takes time to develop.

\section{Storying lesbian lives from Russia and Poland for LGBT History Month}

The first storytelling event was co-organised and led by Elwira Grossman and myself, and hosted at the Glasgow Women's Library (GLW) in mid-February 2012. The event was organised spontaneously, in response to an invitation from the organiser of the Scottish LGBT ${ }^{7}$ History Month. The organiser was aware of my research on the lived experiences of non-heterosexual women in Soviet and postSoviet Russia and of Elwira's work on issues of gender and sexuality in contemporary Polish drama (Stella 2008b, 2010, 2012, 2013; Grossman 2003, 2004, 2005, 2009), and thought our work would fit in well with the programme and aims of the festival. The invitation was an opportunity to explore

\footnotetext{
${ }^{7}$ Lesbian, Gay, Bisexual, Transgender.
} 
our shared interests in gender studies and in the power of stories, and was the result of the many conversations we had before and during the TREEC project. Therefore, we decided to organise a joint event called 'Lesbian lives: stories and memories from Russia and Poland', and to also include it in the TREEC programme.

The choice to hold the event at the Glasgow Women's Library rather than on a university campus reflected a desire to attract a diverse non-academic audience, while at the same time making the most of 'captive audiences' which the event was expected to attract through the GLW's outreach activities and links with feminist and LGBT organisations. The event was advertised widely through LGBT community networks, the GWL and our own contacts, which included migrants and minority ethnic cultural organisations, and was open to 'all interested in the subject regardless of their gender, sexual orientation, ethnic background and political views', as stated in the advertising material. The event highlights how 'knowledge exchange' is often a spontaneous, organic process, and shows that the knowledge produced in universities is often seen from the outside as relevant to 'real' communities and issues. Thus, responding and actively creating opportunities to engage with diverse publics does not necessarily mean yielding to the pressures of regulation and commodification (Burawoy 2011): it can be a way of supporting already existing 'communities of learning' and to foster critical publics outside of academic institutions.

The format of the event, suggested by the organiser of LGBT History Month, consisted of two talks of 30-40 minutes, followed by time for questions and discussion. The content of the talks was based on my research on lesbian relations in Soviet Russia and on Elwira's work on the representation of gender and sexuality in contemporary Polish media and literature. The aim of the event, however, was not the conventional 'dissemination'of research findings to non-academic audiences: the use of stories of lesbian women from Russia and Poland was intended to open up a space for intercultural dialogue around issues that transcend national, linguistic and cultural boundaries, such as gender and sexual equality and human rights. The session also offered an opportunity to experiment with more engaging and entertaining ways of presenting academic work loosely based on storytelling techniques. A deliberate effort was made to move away from the standard academic talk: the sociohistorical context of communist and post-communist Russia and Poland was kept to a minimum, while the talks centred on the life stories of a handful of lesbian and bisexual women from Russia and Poland, drawing on published material and literary texts in Elwira's case and on oral history interviews in mine. In an attempt to experiment with storytelling techniques, I edited two interview scripts so that they could be presented as stories; this involved rearranging the key life events 
interviewees talked about so as to have a chronologically ordered and engaging plot. The script of the talk was a mixture of direct quotes from the interviews and connecting passages I wrote to fill in the gaps in between and give the audience a flavour of what life was like in Soviet Russia. The decision to story interview scripts was motivated by a personal frustration with conventions of academic dissemination, which demand editing the very personal, rich and emotional content of life stories and using them as 'evidence', ironing out ambiguities and editing out emotions. Storying the interviews required translating and heavily editing the interview transcripts, and the end result was not necessarily more a more 'authentic' representation of women's lives than academic articles based on interview data. The 'plotted' transcripts did away with social theory jargon and with the academic commentary; as a result, the stories gained in immediacy and accessibility. Nonetheless, women's voices were constantly juxtaposed to the voice of the researcher turned narrator, who in this instance also acted as cultural mediator by 'footnoting' the narrative where needed ${ }^{8}$. However, storying the interview scripts meant tapping into the potential stories have to affect and move, as well as represent, and to promote a deeper, empathic understanding of an issue. In this respect, the stories told seemed to resonate with members of the audience on a very personal level, as their comments indicate:

'As a Hungarian, lesbian university student I really appreciated this program. I'm glad they organized a program which focused on the Eastern-European lesbians' life' [Ireland-based Hungarian participant, via her blog]

'[The event] has inspired me to follow through with the bit I have learned and talk to some other women and seek out other stories' [Scottish participant, feedback form]

Indeed, one of the most rewarding aspects of organising the event was that it was well received by a diverse audience. The cosy, warm space the GLW made available was full to capacity on the night; the audience numbered about 40 people, and included a diverse range of people. The audience comprised young people linked to the organisation LGBT Youth Scotland, regular attendees of the GLW, a few colleagues and students from the university, and individuals who had heard about the event through minority ethnic community networks, some of whom were from an Eastern European background. Although its events are occasionally open to both women and men, the GWL is normally a women-only space; we deliberately stressed that the event was open to anyone interested regardless of their gender. While not disputing the historical importance of having

\footnotetext{
${ }^{8}$ Explanations of the Russian context were kept to a minimum by using pictures to graphically illustrate aspects of life in the Soviet Union.
} 
women-only spaces, one of the aims of the TREEC initiative was to engage diverse audiences and to create hybrid spaces and opportunities for dialogue across cultural boundaries and social divides, and we found it refreshing to have a few men in the audience, which, as expected, was predominantly female.

The audience remained very attentive and engaged throughout the event, and seemed to take in and enjoy the stories; on the feedback forms collected by LGBT History Month the event scored highly for enjoyability, relevance and accessibility. With hindsight, we could see that the talks+Q\&A format of the event allowed for limited audience participation, particularly as it engendered certain expectations and responses in the audience, who during the discussion time addressed us questions as the academic 'experts', and in the feedback forms participants also stressed the 'academic' character of the event. There is certainly scope in future to draw on the arts-based participatory methods successfully used in other parts of the TREEC project in order to encourage the active participation of the audience by soliciting their own stories and involving them in the production of outputs. I also wondered to what extent the stories shared on the night could really live up to the TREEC's initiative's aim of 'translating cultures'. This in itself is a problematic idea, since it implies that cultural exchanges can be boiled down to a relatively straightforward exercise of linguistic translation and cultural footnoting, downplaying the importance of audience interpretation and engagement with concrete stories. For me, the event raised issues around what is involved in retelling 'the lives of others', what are the uses, benefits and limitations of doing this, and how we can address issues of representation, authenticity and legitimacy involved in revisiting, editing and performing stories and memories. The focus and scope of the present article does not allow a fuller engagement with these issues; nonetheless, as academics/social scientists increasingly engage with various forms of storytelling (Mai 2011; Berger and Quinney 2005; Taylor 2010), it is important to reflect on the work that stories can (and cannot) productively perform in the context of research and related knowledge exchange initiatives.

\section{The main event(s): Translating Storytelling}

The second set of events was much more focussed on storytelling as performance and on how stories travel across linguistic and geographical boundaries, and was led by a group of professional storytellers. As experts in the craft, the storytellers were in charge of coordinating and staging their performances, whilst academic staff provided logistical and organisational support. The first event, held at Glasgow's St Mungo's Museum, served as a general dress rehearsal, and it was followed by a 
second event hosted by the Edinburgh Scottish Storytelling Centre. The line-up included two storytellers from Scotland (Ewan McVicar and James MacDonald Reid) and one from Poland (the Warsaw-based Michat Malinowski), with the additional participation of Frances Logan for the Glasgow performance only ${ }^{9}$; all the Scottish storytellers involved had previous experience of performing or collecting stories in Central and Eastern Europe or Russia. The events were free and deliberately held outside of university premises to have a broader reach: we drew on host and patner insitutions' mailing lists and active contacts to advertise the events, which attracted as expected members of their established audiences. . In Glasgow, the event was co-organised with the Curious project, a Lottery-funded arts project based at St Mungo's Museum of Religious Life and Art, whose remit is to celebrate the diversity of the museum's collections and of the people of Glasgow by creating intercultural dialogue; this was reflected in the conspicuous participation of migrants from different ethnic communities (including a group of Poles) as well as by a diverse crowd linked to the Museum and to the storytelling community. In Edinburgh, the event was advertised by the Scottish Storytelling Centre, attracting regular attendees of the centre, students and punters variously associated or interested in Central and Eastern Europe.

Both the Glasgow and the Edinburgh events featured the performance of folktales from Central and Eastern Europe and Scotland, interspersed with reflections about how stories are told and listened to in different socio-cultural contexts, and on their experiences of collecting and translating stories from different parts of the world. Although the practice of sharing stories across geographic and linguistic borders is common among storytellers, the explicit articulation of reflections on the theme is unusual in storytelling events, and was included at the request of the academic staff. The leaflet advertising the events gestured towards storytelling as a way to bridge distances between geographical and cultural boundaries, a theme that had recurred in the many interesting discussions we had with the storytellers involved:

Can storytelling connect us if we speak different languages? Can it cross geographic frontiers and bring us closer together? Can we find ourselves in stories told by speakers of other tongues?

\footnotetext{
${ }^{9}$ Ewan McVicar, James MacDonald Reid and Frances Logan are members of the Scottish Storytelling Network, a directory created by the Scottish Storytelling Centre in Edinburgh

(http://www.scottishstorytellingcentre.co.uk/). Michał Malinowski is a Polish storyteller and the founder of the Storytelling Museum of Poland, based in Warsaw (http://www.artofstorytellingshow.com/2009/12/16/michalmalinowski-storytelling-museum-poland/).. All storytellers have been named in recognition and appreciation for the work they did on the project, and with their consent.
} 
The repertoire consisted of folktales and fairytales, whose storylines are typically very simple and linear; as one of the storytellers put it, folktales are about what people say and do, not about what they think or feel. All storytellers reflected on the fact that, through their travels across Europe and beyond, they had come to the realisation that the same stories are shared across geographic and linguistic borders: for example the story 'Golden hair and the three bears', which Ewan had always considered Scottish, also had a Russian version, as he found out through a visit to the Russian city of Perm', while James found striking similarities between a story he was told in Gaelic by his Scottish great-aunt and a folktale he later learned in Serbia. In this respect, folktales represent in many ways a shared repertoire across languages and cultures, as their narrative structure follows standarsised patterns (Propp 1968).

An interesting tension emerged between the ability of folktales to seamlessly circulate and translate across national borders, and the deep link between storytelling, cultural heritage and local and national identities. The latter point is well illustrated by the story of the Scottish Storytelling Centre itself, as outlined by its current director, Donald Smith, in the introduction of his book Storytelling Scotland: a nation in narrative. Smith shows how SSC's history is very much intertwined with devolution, the creation of the Scottish Parliament and the cultural agendas these events generated, such as the promotion of Gaelic language and the preservation of folktales as part of Scotland's cultural heritage (Smith 2001). Interestingly, however, for both Michał and James, the most welltravelled of the storytellers involved, it was the experience of travelling and encountering other storytelling traditions which had prompted or renewed an interest in their national heritage. Michał's discovery of traditional storytelling while travelling in Papua New Guinea drove him to find out more about oral traditions in rural Poland, of which he had no previous knowledge or experience; this eventually inspired him to found the Storytelling Museum of Poland, 'devoted to the collection, preservation and promotion of oral heritage from all over the world ${ }^{10}$. James emphasised how he was able to relate to folktales from the Balkans because of their similarities with those from the Scottish Highlands he grew up listening to; travelling stimulated him both to tell stories from his native Scotland and to collect and perform stories from other parts of Europe.

The performers also reflected on the ability of storytelling to convey meaning across language and cultural barriers, and its potential to engage diverse publics. Storytelling originates in pre-literate oral tradition, when stories were passed on through word of mouth; storytelling performances include an element of improvisation, as storytellers adlib on standardised plots, rather than reciting the stories by heart. Nonetheless, storytelling is not just about the verbal aspect of a narrative:

${ }^{10}$ http://www.artofstorytellingshow.com/2009/12/16/michal-malinowski-storytelling-museum-poland/ 
stories are sometimes introduced or accompanied by music played on traditional instruments, such as goat herder's pipes, for atmosphere and entertainment, and an important element of a successful performance is interaction with the audience, who is sometimes prompted to join in by repeating refrains or by responding to specific aspects of the story. The style of delivery is culturally specific, and often reflects the particular contexts in which stories originate: James, for example, noted that the use of full physical dramatisation was rare if not entirely absent in the delivery of stories, both in the Scottish Highlands and in rural areas of Southern and Eastern Europe (Bulgaria, Serbia, Slovakia and Georgia). Body language was not prominent in the delivery and reception of the stories: storytellers remained seated and did not attempt to make a physical show of the tale, while people listening to their stories often kept their hands busy with simple crafts or tasks such as knitting or shelling peas. Through their travels and experience of performing internationally for different audiences, storytellers had become aware of the need to adapt their delivery style to suit specific publics. At the same time, untranslated performances in languages that may not be understood by the audience were relatively common in the storytelling community, as Michał demonstrated by telling a story in Polish at the Edinburgh event. Interestingly, Michat's delivery style changed markedly as he shifted from English to his native Polish; whilst the non-verbal elements of the performance were intelligible to all, this raised questions about the extent to which the audience is able to appreciate and enjoy a story in an unknown language without the mediation of some kind of translation or summary.

Folktales plotlines are based on binary oppositions which often emphasise neat boundaries between 'us' and 'the other' (Propp 1968), and the contexts in which they are performed also frequently emphasises heritage and a shared identity, creating insiders and outsiders in the process. For example, the appreciation of many of the Scottish stories told at the Glasgow-based storytellers' gathering Better Crack Club was based on the assumed ability to understand certain Scots words and expressions. Although open to the general public, and occasionally featuring non-Scottish stories from guests and members of the audience the Better Crack Club's identity as a community of practice was very strongly based on a shared interest in and knowledge of Scottish heritage. A parallel can be drawn between the gatherings of the Better Crack club and the 'Lesbian Lives' event organised at the Women's Library. The latter may also have reinforced the perception of a shared identity and the boundary between 'us' (lesbians, women) and 'them' (heterosexuals, men, people not identifying according to binary notions of gender and sexuality), despite the heterogeneous identifications of the speakers and the audience. Indeed, as sociologist Ken Plummer (1995) perceptively argues, stories are crucial in shaping the boundaries of shared identities and 'imagined communities', a point he illustrates with the example of the 'coming out' story, which was crucial in 
creating 'modern' gay and lesbian identity and community in the western world. Thus, with respect to 'translating cultures', storytelling has both positive and negative aspects: it encourages engagement with the local and the particular, and a sympathetic curiosity towards 'own' and 'other' languages and stories, and in multinational, multicultural contexts such as the 'Translating Storytelling' event and the international Festivals organised by the SSC, it teases out universal themes, bridging distances between cultures. At the same time, the emphasis is on the story's delivery rather than its content, and on performers' ability to entertain. The identity narratives it produces may be constraining and stereotypical, and promote only a superficial engagement with 'the other'. For example, some stories portrayed women as either evil witches or submissive members of the 'fair sex', while foreigners and newcomers sometimes featured as the main character's antagonists. This may serve well the story's plot, yet be detrimental to the active, critical engagement of the audience with issues of diversity and with attempts to promote dialogue across social and cultural boundaries.

\section{Conclusions}

Events such as the ones described above may not to register on the scales through which 'impact' is currently measured, as the latter is mainly assessed on indicators such as engagement with policy makers, media coverage and large-scale public events. The chapter has argued, nonetheless, that this kind of events perform an important function in opening up 'expert' knowledge to public discussion and scrutiny, in supporting existing 'communities of learning' and in creating new opportunities to foster critical thinking outside of academic institutions.

Whilst concerns about the sustainability and accountability of the HEls cannot be dismissed altogether, I have argued that a lack of vision about how universities can benefit wider publics creates opportunities for short-sighted approaches which frame 'impact' as a quantifiable commodity to be utilised to bolster institutional and professional credentials. Against prevalent utilitarian perspectives, where 'the general public' is tantamount to the taxpayers, and where state policy-driven agendas are justified in the name of 'public interest', I propose, after Holmwood (2011) that the starting point of these debate should be the idea of the publics (in the plural) as communities of practice. I have argued that 'impact' relates to universities as places of learning as well as research, and that meaningful 'knowledge exchange' should start from an active, receptive and patient engagement with wider publics. These engagements have the potential to be formative for academic staff as well as non-academic partners and audiences, and to sow the seeds for organically emerging, longer term collaborations with non-academic communities. One important 
outcome of the TREEC network initiative is that the contacts established extended beyond the life of the project and produced new collaborations, which in turn made use of skills developed through the TREEC initiative. For example, Michał Malinowski was invited back to Scotland a few months after the 'Translating storytelling' event to perform at the SSC's annual storytelling festival and at St Mungo's museum; the Curious project at St Mungo's established links with an arts practitioner involved in a different strand of the TREEC Network initiative; and new 'Knowledge Exchange' collaborations involving Glasgow University staff have built on contacts and shared skills developed through the TREEC Initiative. This ripple effect was unexpected, and brought home once again the fact that knowledge exchange initiatives can trigger exchanges where information, expertise and skills productively and creatively flow in multiple directions at once. This type of knowledge exchange is at odds with the artificial notion of 'knowledge transfer' as a process where knowledge is imparted to the lay public by knowing academics.

\section{Bibliography}

Berger, R. J. and Quinn, R. (2005) Storytelling sociology: narrative as social enquiry. Lynne Rienner Publishers.

Burawoy, M. (2011) 'Redefining the Public University: Global and National Contexts', in Holmwood, J. (ed) A Manifesto for the Public University. London: Bloomsbury Academic.

Calhoun, C. (2006) 'The University and the Public Good', Thesis Eleven 84(7), 7-43.

Cameron, E. (2012) 'New geographies of story and storytelling', Progress in Human Geography 36(5), 573-592.

Collini, S. (2010) What are Universities for? (London: Penguin Books).

Department for Business, Innovation and Skills (2010) Securing a Sustainable Future for Higher Eductation: an Independent Review of Higher Education Funding and Student Finance (Brown Report), available at http://dera.ioe.ac.uk/11444/1/10-1208-securing-sustainable-higher-educationbrowne-report.pdf, last accessed 18 April 2013.

Dunn, J A 2013 'Review into the present state of Slavonic and East European Studies in the higher education system of the UK'. The Higher Education Academy, York.

Figes, O. (2002) Natasha's Dance: A Cultural History of Russia. London: Allen Lane.

Flynn, M., Kay, R. and Oldfield, J. (eds.) (2008) Trans-National Issues, Local Concerns and Meanings of Post-Socialism: Insights from Russia, Central Eastern Europe and Beyond. Lanham, MD: University Press of America. 
Grossman., E. (2003) 'Czy bedzie miejsce dla nowonarodzonych? Analiza dzenderowa wybranych sztuk polskich pisarek ostatniej dekady', in British Contributions to the 13th International Congress of Slavists, Ljubljana 15 - 21 August 2003.

Grossman, E. (2005) 'Who's Afraid of Gender and Sexuality? Plays by Women', Contemporary Theatre Review 15(1), 105-116.

Grossman, E. (2009) 'Gender Dynamics in Polish Drama after 2000', Women's Writing Online1, 175204.

Henry, A. and McKenzie, S. (2012) 'Brokering Communities of Practice: A Model of Knowledge Exchange and Academic-Practitioner Collaboration Developed in the Context of Community Policing', Policy, Practice and Research 13(4), 315-328.

Holmwood, J. (ed.) (2011a) A Manifesto for the Public University. London: Bloomsbury Academic.

Holmwood, J. (2011b) 'The Idea of a Public University', in Holmwood, J. (ed) A Manifesto for the Public University London: Bloomsbury Academic.

Jump, P. (2012) 'ERC rejects 'impact agenda', Times Higher Education, 8 March 2012, available at http://www.timeshighereducation.co.uk/419276.article, last accessed 18 April 2013.

Kindon, S., Pain, R. and Kesby, M. (2010) Participatory Action Research Approaches and Methods. Connecting People, Participation and Place. London: Routledge.

Liamputtong, P. and Rumbold, J. (2008) 'Knowing Differently: Setting the Scene', in Liamputtong, P. and Rumbold, J. (eds.) Knowing differently: Arts-based and Collaborative Research. New York: Nova Science, 1-23.

Mai, N. (2011) 'Normal: Real Stories from the Sex Industry'. Documentary film.

Martin, B. R. (2011) 'The Research Excellence Framework and the 'Impact Agenda': are we Creating a Frankestein Monster?', Research Evaluation 20(3), 247-254.

Matless, D., Oldfield, J. and Swain, A. (2007) 'Encountering Soviet Geography: Oral Histories of British Geographical Studies of the USSR and Eastern Europe, 1945-1991', Social and Cultural Geography 8(3), 353-372.

Mitton, C., Adair, C.E., McKenzie, E., Patten, S.B. and Perry, B. W. (2007) 'Knowledge Transfer and Exchange: Review and Synthesis of the Literature', The Milbank Quarterly 85(4), 729-768.

Mündel, I. (2003) Radical Storytelling: Performing Process in Canadian Popular Theatre', Theatre Research in Canada 24(1/2).

Nove, A. (1992) An Economic History of the U.S.S.R. London: Penguin Books.

Pain, R., Kesby, M. and Askins, K. (2011) 'Geographies of Impact: Power, Participation and Potential', Area 43(2), 183-188.

Pilkington, H. and Omel'chenko, E. (1997) ' "Zachem mne vrat?" Opyt primeneniia interviu k issledovaniiu russkoiazychnoi migratsii', Rubezh. Almanakh Sotsial'nykh Issledovanii, March. 
Pratt, G. and Johnson, C. (2007) 'Turning Theatre into Law, and Other Spaces of Politics', Cultural Geographies 14(1), 92-113.

Propp, V. (1968) Morphology of the Folktale. Austin: University of Texas Press.

Reay, D. (2004) 'Education and Cultural Capital: The Implications of Changing Trends in Education Policies', Cultural Trends 13:2, pp. 1-14.

Reay, D., David, M.E. and Ball, S. (2005) Degrees of Choice: Social Class, Race and Gender in Higher Education. Stoke-on-Trent: Trentham.

REF2014 (2012) Panel Criteria and Working Methods, January 2012, available at http://www.ref.ac.uk/media/ref/content/pub/panelcriteriaandworkingmethods/01 12.pdf, last accessed 18 April 2013.

Shore, C. and Wright, S. (1999) 'Audit Culture and Anthropology: Neo-Liberalism in British Higher Education', Journal of the Royal Anthropological Institute 5(4), 557-575.

Skeggs, B. (1997) Formations of Class and Gender. London: Sage.

Smith., D. (2001) Storytelling Scotland: A Nation in Narrative. Edinburgh: Polygon.

Stella, F. (2008a) 'Gomofobiia Nachinaetsia Doma', Ostrov, September issue.

Stella, F. (2008b) 'Homophobia begins at home: lesbian and bisexual women's experiences of the parental household in urban Russia', in Healey, D. (ed.) Queer Issue, (June 2008), Kultura, available at http://www.kultura-rus.de/

Stella, F. (2010) 'The language of intersectionality: researching 'lesbian' identity in urban Russia', in Taylor, Y., Hines, S. and Casey. M. (eds.) Theorizing Intersectionality and Sexuality. Basingstoke: Palgrave Macmillan.

Stella, F. (2012) 'The politics of in/visibility: carving out queer space in Ul'yanovsk', Europe-Asia Studies 64(10):1822-1846.

Stella, F. (2013) 'Lesbian lives and real existing socialism in late Soviet Russia', in Taylor, Y. and Addison, M. (eds) Queer Presences and Absences. Basingstoke: Palgrave Macmillan.

Taylor, Y. (2010) 'Stories to Tell? Reflexive (dis)Engagements and (de)Legitimised Selves', Qualitative Enquiry 16(8), 633-641.

Wedel, J. (2001) Collision and Collusion: the Strange Case of Western Aid to Eastern Europe. New York: Palgrave.

Wenger, E. (1998) Communities of Practice: Learning, Meaning and Identity. Cambridge, Cambridge University Press.

Worton, M. (2009) Review of Foreign Language Provision in Higher Education in England. HEFCE. 